\title{
Recent Packaging Applications in Dairy Industry
}

\author{
Sehnaz Ozatay \\ Canakkale Onsekiz Mart University, Ezine Vocational School, Ezine/Canakkale \\ E-mail: sehnazozatay@comu.edu.tr
}

\begin{abstract}
Packaging protects from environmental influences causing deterioration of foods and beverages such as heat, light, the presence or absence of moisture, oxygen, pressure, enzymes, spurious odours, microorganisms, insects, dirt and dust particles, gaseous emissions, and so on. Prolonging shelf-life involves application of various strategies such as temperature control; moisture control; addition of chemicals such as salt, sugar, carbon dioxide, or natural acids; removal of oxygen; or a combination of these with effective packaging (Restuccia et al. 2010). A great technological development for food packaging has been developed over the past few decades to satisfy consumer demands relating to more natural forms of preservation, and methods to control packaging and storage for assurance and food safety (Singh et al. 2011). The potential of modified-atmosphere packaging (MAP) and active packaging to extend the shelf life of different dairy products has been demonstrated (Conte et al. 2008). Active packaging (AP) is, certainly, one of the most important innovations in this field. It is an innovative concept that can be defined as a type of packaging that changes the packaging condition, extending shelf life and improving safety or sensory properties while maintaining food quality (Singh et al. 2011).
\end{abstract}

Key words: active packaging, dairy, food packaging, shelf-life

DOI: $10.7176 / \mathrm{JSTR} / 5-6-04$

\section{Introduction}

A great technological development for food packaging has been developed over the past few decades to satisfy consumer demands relating to more natural forms of preservation, and methods to control packaging and storage for assurance and food safety (Singh et al. 2011). If the choice of the packaging material is improper, undesirable interactions with the packed dairy product might occur resulting in serious concerns about their safety. Over the past 10-15 years several food safety issues on migration of hazardous substances from packaging material into dairy products have been recorded (Scetar et al. 2019). Active packaging (AP) is, certainly, one of the most important innovations in this field. It is an innovative concept that can be defined as a type of packaging that changes the packaging condition, extending shelf life and improving safety or sensory properties while maintaining food quality (Singh et al. 2011). Several natural substances are suitable to develop an active packaging (Conte et al. 2008). One of the potential approaches is the use of active coatings that cover cheese surface with bio-materials containing antimicrobial compounds (Lucera et al. 2014). The main approaches to maintain the food product quality for more time are based on the raw materials quality improvement, on making process innovations, and on the use of suitable storage conditions (Conte et al. 2006).

In recent years the use of packaging system capable to provide safety and quality and prevent the growth of post-processing contaminants in food, by maintaining quality and freshness, has increased considerably. Food packaging systems with antimicrobial properties could play a role in extending food shelf life. Among active polymeric materials, nano-systems containing silver nanoparticles (Ag-NP) have received great attention due to their attractive physico-chemical properties (Mastromatteo et al. 2015). Packaging of dairy products continues to evolve with advances in processing and material technologies, in response to changes in the needs or demands of consumers. Novel dairy packaging systems incorporate new technologies such as nanotechnology and smart packaging (Karaman et al. 2015). 


\section{Modified atmosphere packaging (MAP)}

The atmosphere inside a package can be modified by either passive or active methods. In passive MAP, the rate of change and the final gas composition in the package depend on both the packed product and the permeability of the packaging material. The main disadvantage of passive MAP is that it may require a long storage period to achieve the optimal gas composition, which could be especially important for products with relatively short shelf life. That disadvantage can be overcome with the use of active modification of the atmosphere. Thus, active MAP is usually accomplished by first creating a vacuum and then injecting the desired gas mixture in the package. If packaging material that is used provides adequate barrier with no leakage, the desired atmosphere is directly achieved at the beginning of storage and remains unchanged. The disadvantage of active MAP over passive MAP is the higher cost in equipment and gases (Scetar et al. 2019). Various studies have confirmed that MAP is very efficient in controlling mould development, aflatoxin activity, and shelf life extension of various cheese types (Scetar et al. 2019). When an active ingredient such as an oxygen scavenger is used in combination with MAP it is often referred to as AMAP (active modified atmosphere packaging) (Johansson 2013). Several attempts have been made to control spoilage microflora. Generally, modified atmosphere efficiently inhibited staphylococci, moulds and yeasts, but psychrotrophs were inhibited less or not at all. Recently, other studies have focused on the effective- ness of lysozyme combined with Na-EDTA, natural vegetable antimicrobial substances and chitosan that are well-known agents against grampositive bacteria, coliforms and pseudomonads. (Lucera et al. 2014).

Studies by various researchers have shown that MAP is effective on different cheese types for the control of mold development, aflatoxin formation, and shelf-life extension (Karaman et al. 2015). Cheese is a complex food product consisting mainly of casein, fat, and water. Several researchers have recommended that fresh cheeses (e.g., cream cheese, decorated cream cheese, soft cheese, and cottage cheese) are packaged in modified atmosphere with $\mathrm{N} 2$ and/or $\mathrm{CO} 2$ replacing the $\mathrm{O} 2$ in the package. However, spoilage caused by yeast and especially bacteria may still occur even at very low $\mathrm{O} 2$ and elevated $\mathrm{CO} 2$ levels (Cerqueira et al. 2009). According to the available literature data, $\mathrm{CO} 2$ concentrations between 20 and $60 \%$ are required to inhibit aerobic microbes which are largely responsible for spoilage of unripened soft cheeses. In addition, in whey cheeses it was shown that MAP atmospheres consisting of 30/70, 40/60 and $60 / 40 \mathrm{CO} 2 / \mathrm{N} 2$ had significant inhibitory effect on the studied spoilage microbes with no influence on sensory characteristics of the product (Scetar et al. 2019).

\section{Edible Coatings and Antimicrobial Packaging}

Edible films and coatings can improve shelf life and food quality by providing good and selective barriers to moisture transfer, oxygen uptake, lipid oxidation, losses of volatile aromas and flavors, better visual aspect, and reduction of microbiological contamination. The use of coatings creates a modified atmosphere surrounding the

commodity similar to that achieved by controlled or modified atmospheric storage conditions (Cerqueira et al. 2009). One of the potential approaches is the use of active coatings that cover cheese surface with bio-materials containing antimicrobial compounds (Lucero et al. 2014). Edible coatings have attracted great attentions nowadays, mainly due to the need of relieving the environmental pressure and improving the food quality and safety. Edible coatings can be applied on or even within foods by various methods, and different coating methods possess their own advantages and disadvantages. For good product quality and accurate weight control, coating solution viscosity is a key parameter and the surface of food should better be flat. Spraying is another widely used way for applying coatings. This technique offers uniform coating, thickness control, and the possibility of successive applications which does not contaminate the coating solution (Zhong et al. 2014). Synthetic packaging films have led to serious ecological problems due to their non-biodegradability. The major concern of the consumer for environmental protection led food and packaging industries to increase research in biodegradable food packaging materials. In this context, biopolymers can be an alternative source for packaging materials development due to their biodegradability. Chitosan is one of a few natural cationic polysaccharides that can be derived from crustacean or fungi. Having antimicrobial properties against many bacteria, filamentous fungi and yeast chitosan application as edible film and coating is very attractive (Fajardo et al. 2010).

Natamycin protects the surface of cheese against the development of mould. However, the incorporation of antifungal agents onto food surface by spraying, dipping or coating without matrix may result in partial inactivation of the active substance and a rapid diffusion within the bulk of food. The use of packaging films based on antimicrobial polymers could prove more efficient, by maintaining high concentrations of the active substance on food surface while preventing its migration, thereby maintaining a critical concentration for an extended period of time (Fajardo et al. 2010). 
According to Fajardo et al. 2010, although natamycin has been used for many years, the incorporation of natamycin on chitosan-based films could act as an additional post-processing safety measure, once the inhibitory effect on microbial growth of both components (natamycin and chitosan) is expected to provide protection against a broad spectrum of microorganisms. The controlled release of natamycin from chitosan film would address the limitation of rapid loss of natamycin applied directly on cheese surface.

Among the substances with antimicrobial and antioxidant properties, potassium sorbate, sodium benzoate, calcium lactate and calcium ascorbate are used to prevent deterioration of food products. In the food industry, sodium benzoate and potassium sorbate are often used as preservatives. Sodium benzoate is used as an antifungal agent to conserve margarine, fresh juices and sweets. European Commission thresholds for benzoic acid and sodium benzoate are $0.015-0.5 \%$, respectively. Potassium sorbate is used to preserve cheese, cakes and syrups also at very low concentration accounting for $0.2 \%$ (Lucera et al. 2014).

\section{Nanotechnology}

Lin et al. 2019, aims to increase the stability and prolong action time of moringa oil (MO) by loading in chitosan nanoparticles. Afterwards, electrospinning technique was put into use to carry out the application of moringa oil/chitosan nanoparticles in food packaging purposes. The antibacterial activity of the nanofibers against L. monocytogenes and S. aureus on cheese was also investigated, along with surface color and sensory evaluation. In order to improve the stability and prolong action time of MO, MO was loaded into chitosan nanoparticles. The nanofibers exhibited excellent physicochemical properties. Besides, the nanofibers possessed high antibacterial effect against L. monocytogenes and S. aureus on cheese at $4{ }^{\circ} \mathrm{C}$ and $25^{\circ} \mathrm{C}$ and negligible impact on the surface color and sensory quality of cheese during 4 days storage. Hence, the MO@CNPs embedded gelatin nanofiber was a promising active food packaging material for further food application.

Nanoclay has also been studied for use in packaging material because of its potential as a gas barrier. When well dispersed in the polymer matrix, nanoclays can improves the gas barrier properties of the material. These improvements have led to the development of a nanoclay polymer for packaging processed meats, cheese, confectionery, cereals, boil-in-the-bag foods, as well as in extrusion-coating applications for fruit juices and dairy products (Karaman et al. 2015).

Nanotechnology is outlined as control or manipulation of matter at the atomic, molecular, or organic compound level that affects useful behavior. Nano composites area unit main and major invention of engineering science during which nano materials were wont to improve the barrier properties of plastic wrapping for foods and dairy farm merchandise (Patel et al. 2010).

\section{Biodegradable Packages}

The daily need of food consumption, and therefore, of plastic materials, brought up a demand of researches related to biodegradable packaging in order to replace materials that accumulate for a long time in the environment. Besides that, there is a current trend of gradual withdrawal of non-biodegradable plastics from the composition of disposable plates, cups, trays and cutlery, with their replacement by biodegradable materials, in order to decrease this accumulation. Countries such as France, Costa Rica and, recently Brazil, has already decided to accomplish the fully replacement until 2020, 2021 and 2028, respectively, corroborating an expected growth in biodegradable polymers demand (Lara et al. 2019). Whey protein isolate (WPI) is an edible and biodegradable biopolymer, which can be obtained from the whey generated by cheese industries, and can be used as polymeric matrix for packaging film forming. WPI based films present desirable properties of transparency and good oxygen barrier, since the film forming includes the proteins heating, inducing their denaturation above $50{ }^{\circ} \mathrm{C}$, and thus proteins become insoluble and aggregated. However, these films are commonly brittle, due to the interactions among the different functional groups in protein chains, such as sulfhydryl, amino and carboxylic acid groups exposed during the film forming, producing a more rigid structure (Lara et al. 2019).

\section{Scavengers, Absorbers and Antioxidants}

Of multiple active packaging systems, oxygen absorbers applied in the form of sachets, labels, seals or polymers incorporated directly into the structure of packaging material are the most popular (PanfilKuncewicz et al. 2006).

The carbonic acid gas scavenging bag absorb the occluded carbonic acid gas that otherwise cause the package to burst if not removed throughout storage. Carbon dioxide absorbers contain material such as calcium hydroxide, sodium hydroxide, potassium hydroxide, calcium oxide and silica gel. It has 
applications in coffee, battered goods and cheese (Patel et al. 2010). The absorbers that utilize iron compounds are the simples and the cheapest, thus the most extensively used ones. Oxygen absorbers can be applied alone or in a combination with packaging under modified atmosphere (Panfil-Kuncewicz et al. 2006).

Packaging containing antioxidants is a new generation of packaging material that can release active compounds at controlled rates suitable for reducing the oxidation process in a wide range of foods. This relatively new technology is called active packaging (LaCoste et al., 2005). Although the evidence suggests that antioxidant packaging is a promising technology for protection of whole milk powder, its potential cannot be fully realized unless major technical problems are overcome (Granda-Restrepo et al.2009).

\section{Conclusion}

A food package communicates important information about the product, how to prepare it, and information about the nutritional content. Packaging also allows for consumers to enjoy food the way they want, at their convenience. Food packages can be geared toward a persons own lifestyle through designs like portability and single serving dishes. Although traditional packaging covers the basic needs of food containment, advances in food packaging are both anticipated and expected. Society is becoming increasingly complex and innovative packaging is the result of consumers' demand for packaging of dairy products that is more advanced and creative than what is currently offered. Active packaging and intelligent packaging are the result of innovating thinking in packaging.

\section{References}

1. Cerqueira M.A., Lima A.M., Souza B.W.S., Teixeira J.A., Moreira R.A. And Vicente A.A. (2009) "Functional Polysaccharides as Edible Coatings for Cheese" J. Agric. Food Chem., 57:14561462.

2. Conte A., Scrocco C., Sinigaglia M. and Del Nobile M. A. (2007), "Innovative Active Packaging Systems to Prolong the Shelf Life of Mozzarella Cheese", Journal of Dairy Science, 90(5): 2126213.

3. Conte A., Gammariello D., Di Giulio S., Attanasio M. and Del Nobile M. A. (2009), Active coating and modified-atmosphere packaging to extend the shelf life of Fior di Latte cheese", Journal of Dairy Science, 92(3): 887-894.

4. Fajardo P., Martins J.T., Fuciños C., Pastrana L., Teixeira J.A., Vicente A.A. (2010), "Evaluation of a chitosan-based edible film as carrier of natamycin to improve the storability of Saloio cheese", Journal of Food Engineering, 101 349-356.

5. Granda-Restrepo D., Peralta E., Troncoso-Rojas R., Soto-Valdez H. (2009) "Release of antioxidants from co-extruded active packaging developed for whole milk powder" International Dairy Journal, 19: $481-488$.

6. Johansson K. (2013), "Oxygen-reducing enzymes in coatings and films for active packaging" Karlstad University Studies, Universitetstryckeriet, Karlstad, 38: 1-106.

7. Karaman A.D., Özer B., Pascall M.A., Alvarez V., (2015) "Recent Advances in Dairy Packaging" Food Reviews International, 31(4): 295-318.

8. Laraa B.R.B., Araújoa A.C.M.A., Diasb M.V., Juniorc M.G., Santosb T.A., Ferreiraa L.F., Borges S. V. (2019), "Morphological, mechanical and physical properties of new whey protein isolate/ polyvinyl alcohol blends for food flexible packaging" Food Packaging and Shelf Life, 19: 16-23.

9. Lin L., Gu Y., Cui H., (2019), "Moringa oil/chitosan nanoparticles embedded gelatin nanofibers for food packaging against Listeria monocytogenes and Staphylococcus aureus on cheese", Food Packaging and Shelf Life, 19:86-93. 
10. Lucera A., Mastromatteo M., Conte A., Zambrini A.V., Faccia M., Del Nobile M.A., (2014) "Effect of active coating on microbiological and sensory properties of fresh mozzarella cheese" Food Packaging and Shelf Life I: 25 - 29.

11. Mastromatteo M., Conte A., Lucera A., Saccotelli M.A., Buonocore G.G., Zambrini A.V., Del Nobile M.A. (2015), "Packaging solutions to prolong the shelf life of Fiordilatte cheese: Biobased nanocomposite coating and modified atmosphere packaging" LWT - Food Science and Technology, 60: 230-237.

12. Panfil-Kuncewicz H., Staniewski B., Szpendowski J., Nowak H. (2006) “Application Of Active Packaging To Improve The Shelf Life Of Fresh White Cheeses" Polish Journal of Food and Nutrition Sciences, 15/56: 165-168.

13. Patel R., Prajapati J.P. and Balakrishnan S., (2018), "Packaging Trends of Dairy and Food Products" Journal of Food and Dairy Technology, 6(1):1-9.

14. Restuccia D, Spizzirri U.G, Parisi O.I, Cirillo G, Curcio M, Iemma F, Puoci F, Vinci G, Picci N. (2010) "New EU regulation aspects and global market of active and intelligent packaging for food industry applications" Food Control, 21:1425-1435.

15. Scetar M., Barukcic I., Kurek M., Jakopovic K.L., Bozanic R., Galic K. (2019), "Packaging perspective of milk and dairy products", Mljekarstvo, 69 (1): 3-20.

16. Singh P., Wani A.A., Saengerlaub S., (2011), “Active packaging of food products: recent trends" Nutrition and Food Science, 41(4): 249-260.

17. Zhong Y., Cavender G., Zhao Y. (2014) "Investigation of different coating application methods on the performance of edible coatings on Mozzarella cheese" LWT - Food Science and Technology, 56:1-8.

Sehnaz Ozatay She was born in Izmir/Turkey, 1976. She was graduated at Ege University, Food Engineering Department in Izmir/Turkey in 1998. She got her MSc degree at Ege University, Food Engineering Department, in Izmir/Turkey in 2001. She got her PhD degree at Ege University, Science Institute, Biotechnology Department, in Izmir/Turkey in 2007. The author's major field is Food Technology and Biotechnology. 